\title{
Application of Ceramic Membrane in Wastewater Treatment
}

$$
\text { Yuze } \mathrm{LI}^{1, \mathrm{a}} \text {, Shoubin ZHANG }{ }^{1, \mathrm{~b}^{*}} \text {, Huajun SUN }{ }^{2, \mathrm{c}}
$$

${ }^{1}$ School of Civil Engineering \& Architecture, University of Jinan, NO.336, Nanxinzhuang West Road, Jinan 250022, P.R.China

${ }^{2}$ Advanced Ceramic Institute, Zibo New \& Hi-tech Industrial Development Zone, Zibo 255000, P.R.China

a353783658@qq.com, b* Corresponding author: cea_zhangsb@ujn.edu.cn, c174051406@qq.com

Keywords: Ceramic membrane; oily waste-water; printing and dyeing waste-water Abstract. Ceramic membrane as an environment-friendly technology, is widely used in water treatment. In this paper, the structure and characteristics of the ceramic membrane are discussed. The application of the ceramic membrane in waste-water treatment is mainly discussed. It mainly includes the treatment of oily waste-water, the treatment of printing and dyeing waste-water and the treatment of degreasing liquid. Finally, the future research direction of ceramic membrane is put forward.

\section{Introduction}

Membrane separation technology is considered one of the most promising water treatment technologies in the 21 st century. According to the different membrane pore size, membrane separation technology can be divided into microfiltration, ultrafiltration, nanofiltration and reverse osmosis; depending on the membrane material can be divided into organic film and inorganic film. Compared with organic film, inorganic ceramic membrane has been widely used in water and waste-water treatment in recent years because of its high temperature resistance, acid and alkali resistance, good stability, high mechanical strength, large flux and long life.

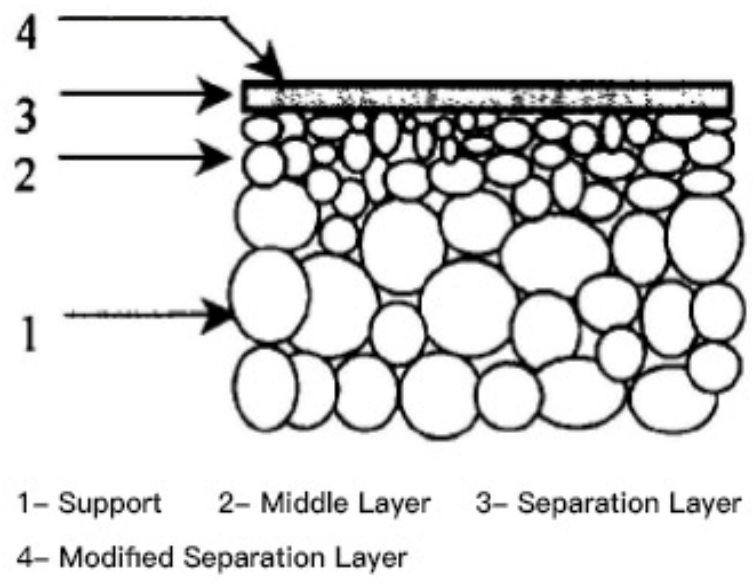

Fig. 1-1 The structure diagram of ceramic membrane

\section{Ceramic membrane structure and characteristics}

\section{Ceramic membrane structure}

Ceramic membrane is an inorganic film, which is coated on the surface and fired at high temperature. It was supported by porous ceramic and an empty ceramic membrane is used as its filter layer. Commercialized ceramic membranes typically have a three-layer structure ${ }^{[1]}$, including a porous support layer, a transition layer, a separation layer, and also can be called as supports, intermediate layers and films.

Support ${ }^{[2]}$ is used to provide support for the film as named, and is also the basis 
for preparation of ceramic membrane. So, the support should have good stability and mechanical strength. According to the different support, ceramic membrane configuration $^{[3]}$ is divided into flat, tube, multi-channel three. The transition layer $^{[4]}$, also known as the middle layer, is located in the middle part of the three-layer structure, the main role is to prevent the film during the preparation of particles to the support of the infiltration. The separation layer ${ }^{[5]}$, as well as known as the film, is the core structure of the ceramic membrane that mainly with the separation function, directly involved in the membrane separation process.

\section{Ceramic membrane characteristics}

The first major advantage of ceramic membrane is a good chemical stability, and can be used in a variety of acidic alkaline and corrosive liquids ${ }^{[6]}$. The second advantage is that the mechanical strength of the ceramic membrane is great. It is not easy to break in a variety of environments ${ }^{[7]}$, and maintain continuous and stable operation of the system. In addition, the ceramic membrane also has a strong anti-microbial capacity, which can effectively inhibit the growth of bacteria. Ceramic membrane with a narrow pore size distribution characteristics have a higher separation efficiency in the practical application at the same time.

Ceramic membrane's biggest drawback lies in its brittle, and the production cost is high, intolerant alkali, so that the promotion of ceramic film suffered a certain degree of restrictions.

\section{Application of Ceramic Membrane in Water Treatment}

\section{Study on Treatment of Oily waste-water by Ceramic Membrane}

As a common pollution oil pollution is harmful greatly to environmental protection and ecological balance. Oily waste-water in industrial production mainly includes oil field water, oil refining effluent, waste water discharged from petrochemical plants, machinery manufacturing waste-water, food processing and production waste water.

The experimental study found that the use of organic film and ceramic membrane on the oil recovery of heavy oil processing, ceramic membrane treatment better; use of self-made $\alpha-\mathrm{Al}_{2} \mathrm{O}_{3}$ ceramic membrane oil $100 \mathrm{mg} / \mathrm{L}$ emulsified oil waste-water removal rate of up to $99 \%$; the removal rate of oilfield waste-water treatment with super / micro / nanofiltration ceramic membrane can reach more than $99.5 \%$. It can be found that the ceramic membrane in the treatment of oily waste-water has a strong competitive edge.

The separation of inorganic membrane is achieved by using membrane pore and lipophilic membrane surface. The separation mechanism is to separate the water and oil by the sieving of the membrane pores and the demulsification of the lipophilic membrane surface to realize the process of oil-water separation. Mainly through the experiment to explore the appropriate ceramic membrane separation operating conditions and membrane cleaning methods for the membrane treatment of oily waste-water to provide the appropriate theoretical basis.

With the operation of stable, good water quality, small footprint, easy expansion, 
the normal work does not consume chemicals, do not produce new sludge and recovery of oil quality is better and so on. Ceramic membrane with acid, alkali, corrosion resistance, resistance to organic solvents and other prominent advantages, and easy cleaning, membrane flux, long service life.

\section{Study on Treatment of Printing and Dyeing waste-water by Ceramic Membrane}

Dyeing waste-water composition is complex, difficult to deal with and emissions, waste-water treatment is a major difficulty. Dye and bleaching and dyeing waste-water generally contains a large number of small molecules of organic matter and nitrite, ferrous salt, sulfide and other organic matter, and the color is deep, alkaline, difficult to handle, then how to control printing and dyeing waste-water has become the focus of the study.

Due to the complex composition of printing and dyeing, a single treatment technology can not achieve the desired effect, so scholars will focus on the combination of multi-technology combination. At present, multi-technology combined treatment of printing and dyeing waste-water has become a development trend. At the same time, because the dyeing rate of the dyeing and printing plant is extremely low, the utility is not enough, the research direction of the scholars is gradually transferred to the water reuse technology, and the dyeing and finishing waste-water treatment effect is improved from various directions.

Ma Chunyan, Yang Bo et $\mathrm{al}^{[8]}$. Demonstrated that the process of hydrolytic acidification - aerobic biochemical - biofilter - ceramsite filtration - ceramic membrane filtration process, the treatment of light pollution water, and used in the production process to meet the quality requirements. Donghua University research group $^{[9]}$ developed a ceramic film-based, combined with other means of governance and separation of the combination of patented equipment, after the deep treatment of waste water into the printing and dyeing production process, and the quality of the product has no effect.

Although the study of inorganic ceramic film has made great progress, but for the treatment of printing and dyeing waste-water, if you want to dye and waste-water treatment in the field and even more widely used in industry, there are many questions need to be solved.

\section{Conclusion}

Inorganic ceramic membrane filtration technology is a new separation technology ${ }^{[10]}$, the application prospect is broad, by the domestic and foreign scholars of widespread concern. As the ceramic membrane has many organic film does not have the advantages and performance, so the future research direction can also be extended to the following aspects:

(1)Ceramic membrane itself due to expensive, resulting in a high cost, waste of the future should be developed low-cost high-performance membrane materials. From the cost of the source to reduce the cost of ceramic membrane to improve, applied to more areas, can be better to promote and use.

(2)Improve the film processing technology to improve the separation efficiency 
of ceramic membrane and permeability, as far as possible to reduce membrane pollution, to achieve the ceramic membrane regeneration and life extension.

(3)Ceramic membrane brittleness also need to focus on the solution, with the more appropriate process integration processing technology, the ceramic membrane to play better.

\section{Acknowledgments}

This work was financially supported by the Shandong Provincial Key Research and Development Program(2016CYJS07A03-2), Shandong Provincial Natural Science Foundation, China (ZR2015EM021), Doctoral Foundation of University of Jinan (XBS1432) and partly supported by National Natural Science Foundation of China (51678276).

\section{References}

[1] Feng Wang,Zhipeng Xie,Fenling Qian. Progress in Preparation of Porous Ceramic Membrane Support[J]. Bulletin of the Chinese Ceramic Society,2012,31(2):285-290.

[2] Jiansheng Li,Xiuyun Sun,Lianjun Wang. Preparation of Multi - channel A12O3 Ceramic Membrane Support[J]. Materials Review,2001,15(9):72-73.

[3] Jilun Yao,Xing Zhang,Zhen Zhou. Research Progress of Ceramic Membrane Technology in Water Treatment[J]. Journal of Chongqing University of Technology (Natural Science), 2016(12):69-74.

[4] Wei Fu,Linlin Guo,Minghua Chen. Research Status and Development Prospect of Composite Ceramic Membrane[J].Porcelain,2006(12):5-7.

[5] CHRISTIAN G G,ANNE C J,ANDRE A. Design of Nanosized Structure Insol-gel Derived Porous Solids. Appli-cations in Catalyst and Inorganic Membrane Preparation[J]. Journal of Materials Chemistry, 1999(9):55-65.

[6] Li Xu, Wenping Li. Application of Ceramic Membrane in Dyeing and Dyeing waste-water Treatment[J]. Chemical machinery, 2000,(3):132-134.

[7] Yi Zhang, Runnan Gu. Treatment of PVA Desizing waste-water by Dynamic Ceramic Membrane[J]. Journal of Donghua University (Natural Science Edition),2007,33(2):236-238.

[8] Chunyan Ma, Bo Yang, Jihua Chen. Pilot Water Treatment Technology for Knitting Dyeing waste-water Treatment[J].Technology of Water Treatment,2008,34(5):74-76.

[9] Danli Xi. China's International Textile New Technology Exhibition[Z].Beijing,2008-03.

[10] Huichao Wen,Li Shu,Weihong Xing. Application of Inorganic Ceramic Membrane in Deaerator waste-water Treatment[J].Technology of Water Treatment,2007,33(3):42-88. 